\title{
Successful pregnancy after in vitro fertilization in an ABO-incompatible kidney transplant recipient receiving rituximab: a case report
}

Akihiro Kosoku', Junji Uchida ${ }^{1 *}$, Keiko Maeda², Yuki Yoshikawa ${ }^{3}$, Akihiro Hamuro ${ }^{4}$, Hisao Shimada ${ }^{1}$, Kazuya Kabei ${ }^{1}$, Shunji Nishide', Tomoaki Iwai', Nobuyuki Kuwabara', Toshihide Naganuma', Norihiko Kumada5',

Yoshiaki Takemoto ${ }^{1}$ and Tatsuya Nakatani ${ }^{1}$

\begin{abstract}
Background: Successful pregnancy outcomes after in vitro fertilization in kidney transplant recipients have been reported, but few cases of successful pregnancy after ABO-incompatible kidney transplantation have been described. Herein, we report on a successful pregnancy after in vitro fertilization in an ABO-incompatible kidney transplant recipient with rituximab, focusing on the changes in immunity.

Case presentation: A 35-year-old woman with end-stage kidney disease caused by IgA nephropathy was referred for kidney transplantation and successfully underwent an ABO-incompatible living-donor kidney transplant using rituximab from her 66-year-old father at the age of 36. Because she and her husband desired childbearing, they received fertility treatments, and embryo cryopreservation was performed before transplantation. Two years after the transplant, she desired pregnancy. Although immunoglobulin levels such as $\operatorname{lgG}$, IgA and IgM had recovered to almost normal range, the peripheral $\mathrm{CD}_{1} 9^{+}$cells and $\mathrm{CD}_{2} \mathrm{O}^{+}$cells remained depleted. At 6 months after conversion from mycophenolate mofetil to azathioprine, frozen embryo transfer was performed during the hormone replacement cycle.

At 37 weeks and 4 days gestation, a healthy baby girl weighing $2220 \mathrm{~g}$ was delivered by cesarean section for arrest of labor. There were no complications in both the recipient and her baby during the perinatal period. At 5 years after the transplant, the recipient has had no major complications including rejection or infection.
\end{abstract}

Conclusions: It is possible for women receiving ABO-incompatible kidney transplantation with rituximab to successfully become pregnant and deliver a heathy baby after in vitro fertilization, if IgG levels recover to normal range despite depleted peripheral blood B cells.

Keywords: Kidney transplantation, Pregnancy, In vitro fertilization, Rituximab, ABO-incompatible

\footnotetext{
*Correspondence: uchida@msic.med.osaka-cu.ac.jp

'Department of Urology, Osaka City University Graduate School of Medicine,

1-4-3, Asahi-machi, Abeno-ku, Osaka 545-8585, Japan

Full list of author information is available at the end of the article
}

(c) The Author(s). 2019 Open Access This article is distributed under the terms of the Creative Commons Attribution 4.0 International License (http://creativecommons.org/licenses/by/4.0/), which permits unrestricted use, distribution, and reproduction in any medium, provided you give appropriate credit to the original author(s) and the source, provide a link to the Creative Commons license, and indicate if changes were made. The Creative Commons Public Domain Dedication waiver (http://creativecommons.org/publicdomain/zero/1.0/) applies to the data made available in this article, unless otherwise stated. 


\section{Background}

Chronic kidney disease is often accompanied by sexual dysfunction and infertility in women patients as a consequence of kidney failure-related endocrine aberration. Even if they become pregnant, the incidence of spontaneous abortion, premature birth and intrauterine growth restriction is high $[1,2]$. For these patients, kidney transplantation is an important option, as it significantly improves fertility rate and fetal and maternal outcomes [3]. In Japan, ABO-incompatible kidney transplantation (ABO-IKT) has been performed since the late 1980's. $\mathrm{ABO}-\mathrm{IKT}$ is immunologically a high-risk procedure because of antibody-mediated rejection due to anti-A/B antibodies. Few cases of successful pregnancy after ABO-IKT have been described [4-6], one of which was a pregnancy after in vitro fertilization (IVF) in an ABOIKT recipient with rituximab [6]. Herein, we report on a case of successful pregnancy after IVF in an ABO-IKT recipient with rituximab, focusing on the changes in immunity during pregnancy.

\section{Case presentation}

A 35-year-old woman, gravida 1, para 0 , with end-stage kidney disease caused by IgA nephropathy was referred for kidney transplantation. Hemodialysis was initiated when she was 33 years old. She first became pregnant after starting hemodialysis and experienced spontaneous abortion at 5 months after initiation of hemodialysis. After experiencing spontaneous abortion, she received fertility treatments and tried in timed intercourse with fertility drugs. She decided to receive kidney transplantation in order to restore fertility. Embryo cryopreservation was performed considering her age before her first visit to our hospital, because she and her husband desired childbearing. She underwent an ABO-incompatible living-donor kidney transplant using rituximab from her 66-year-old father at the age of 36. Initial anti-A antibody titers were 1:128 (IgM) and 1:128 (IgG). Because she underwent two doses of rituximab infusion $(150 \mathrm{mg} /$ $\mathrm{m}^{2}$ on day 14 before and at transplantation) for B cell depletion and four courses of plasma exchange and double filtration plasmapheresis to remove antibodies, anti-A antibody titers were reduced to $1: 8$ (IgM) and 1:8 (IgG). She received maintenance immunosuppressive therapy including cyclosporine, mycophenolate mofetil and methylprednisolone after transplantation. The serum creatinine level increased from 1.3 to $1.6 \mathrm{mg} / \mathrm{dl}$ on the postoperative day 18. Two years after the transplant, because she had no rejection during the past year and had adequate and stable graft function with no acute infections as well as stable maintenance immunosuppression, she desired pregnancy. Although immunoglobulin levels such as IgG, IgA and IgM had recovered to almost normal range, the peripheral $\mathrm{CD} 19^{+}$cells and
$\mathrm{CD}^{+}{ }^{+}$cells remained depleted (Fig. 1). At 6 months after conversion from mycophenolate mofetil to azathioprine, frozen embryo transfer was performed during the hormone replacement cycle.

During pregnancy, the serum creatinine level was 0.8$1.0 \mathrm{mg} / \mathrm{dl}$, and blood pressure was $120-130 / 70-80$ $\mathrm{mmHg}$. Although the cyclosporine trough level decreased to approximately $50 \mathrm{ng} / \mathrm{ml}$ after the 10 th week of pregnancy, the dose of cyclosporine was not adjusted, because pregnancy seems to be a state of immunological tolerance associated with immunosuppressant activity of lymphocytes which creates tolerance to fetus [7]. The serum creatinine level elevated to $1.15 \mathrm{mg} / \mathrm{dl}$ at 36 weeks and 3 days gestation, and labor was induced at 37 weeks and 1 day gestation. At 37 weeks and 4 days gestation, a baby girl weighing $2220 \mathrm{~g}$ was delivered by cesarean section for arrest of labor, with Apgar scores of 8 and 9 at 1 and $5 \mathrm{~min}$, respectively. The baby exhibited no malformation and was healthy. Serum IgG and IgM levels in the maternal cord blood were 912 and $16 \mathrm{mg} / \mathrm{dL}$, respectively. The serum creatinine level improved to approximately $0.8-1.0 \mathrm{mg} / \mathrm{dl}$ after childbirth without treatment. Her blood pressure was stable until delivery but elevated to approximately $160 / 100 \mathrm{mmHg} 4$ days after childbirth, and she required antihypertensives for two weeks. She did not breastfeed her baby. Depletion of the peripheral blood $\mathrm{CD} 19^{+}$cells and $\mathrm{CD} 20^{+} \mathrm{B}$ cells due to administration of rituximab continued during pregnancy (Fig. 1). After pregnancy, anti-A antibody titers were 1:2 (IgM) and 1:2 (IgG). There were no complications in both the recipient and her baby during the perinatal period. At 5 years after the transplant, the recipient has had no major complications including rejection or infection, while the peripheral blood $\mathrm{CD}_{1}{ }^{+}$cells and CD $20^{+} \mathrm{B}$ cells remain depleted due to administration of rituximab, and she is in good clinical condition with only mild renal insufficiency (serum creatinine $1.47 \mathrm{mg} / \mathrm{dL}$ ) (Table 1). She said that she was completely happy with childbirth after kidney transplantation and is satisfied with childcare.

\section{Discussion and conclusions}

Kidney transplantation is an important option for women with end-stage kidney disease contemplating pregnancy [8]. Pregnancy after kidney transplantation is proof of success, although it is not devoid of risks such as preterm birth, low birth weight and small for gestational age. ABO-IKT has become an established form of renal replacement therapy. Recently, Rao NN et al. reported a case of successful pregnancy after IVF in an $\mathrm{ABO}-\mathrm{IKT}$ recipient receiving rituximab [6]. In this present case, we demonstrated a successful pregnancy after IVF in an ABO-IKT recipient with rituximab, focusing on the changes in immunity. Pregnancy in ABO- 


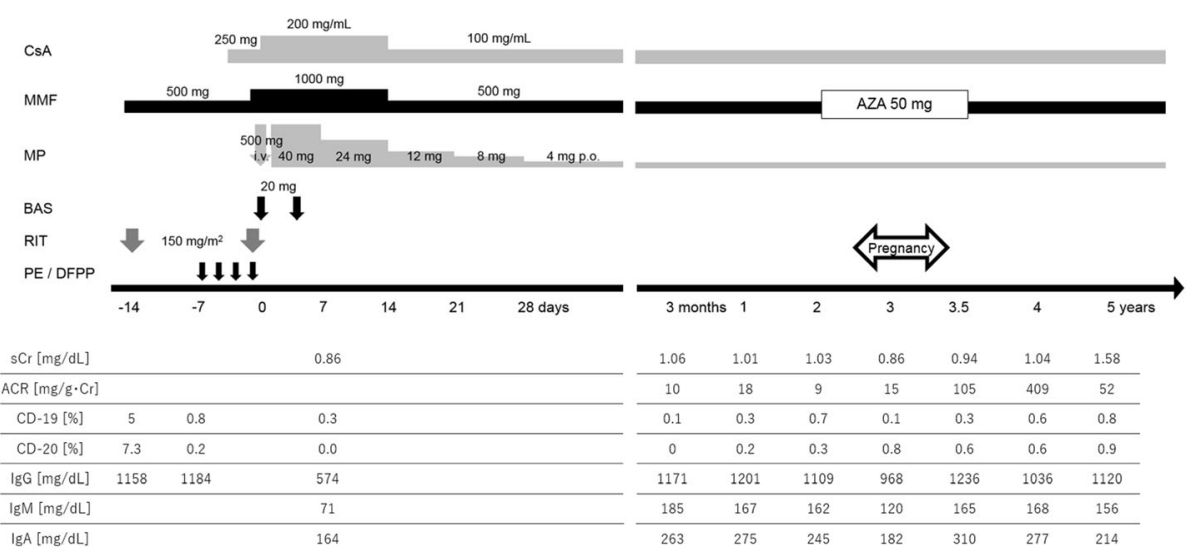

Fig. 1 Immunosuppressive therapy, and changes in immunity and renal functionCsA; cyclosporine, MMF; mycophenolate mofetil, MP; methylprednisolone, BAS; basiliximab, RIT; rituximab, PE; plasma exchange, DFPP; double filtration plasmapheresis, AZA; azathioprine, sCr; serum creatinine, $A C R$; albumin to creatinine ratio

IKT recipients receiving rituximab may be achieved, if IgG levels recover to normal range despite depleted peripheral blood B cells.

In this case report, we evaluated the changes in immunity such as IgG, IgM, IgA and $\mathrm{CD}_{1} 9^{+}$and $\mathrm{CD} 20^{+} \mathrm{B}$ cells in the peripheral blood. Desensitizing with apheresis and rituximab-based immunosuppression decreased IgG levels and the number of $\mathrm{CD} 19^{+}$and $\mathrm{CD} 20^{+} \mathrm{B}$ cells in the peripheral blood at 7 days after transplantation. IgG returned to normal levels at 3 months after transplantation, but $\mathrm{CD} 19^{+}$and $\mathrm{CD} 20^{+} \mathrm{B}$ cell depletion was prolonged during pregnancy. It was previously reported that patients given rituximab may develop transient hypogammaglobulinemia and/or delayed B-cell reconstitution, and therefore should be routinely monitored for serum IgG, IgM and IgA as well as B-cell counts $[9,10]$.
Moreover, pregnant patients who developed transient hypogammaglobulinemia after rituximab should be monitored with neonatal serum IgG, and it might be better to avoid pregnancy after ABO-IKT with administration of rituximab until the patient recovers from hypogammaglobulinemia. We have experienced some patients with prolonged (over 3 years) peripheral B cell suppression after rituximab administration [11]. We routinely verified peripheral $\mathrm{CD} 19^{+}$and $\mathrm{CD} 20^{+} \mathrm{B}$ cell count after kidney transplantation, because this patient wanted to become pregnant.

Favorable outcomes of pregnancies after IVF are commonly reported, although IVF pregnancies are associated with an increased risk of preterm births, very low birth weight and small for gestational age compared with pregnancies after spontaneous conception due to the

Table 1 Medical history timeline

Dates

5 months after dialysis initiation

27 months after dialysis initiation

8 months before transplantation

Dates

28 months after dialysis initiation

7 months before transplantation

35 months after dialysis initiation

25 months after transplantation

15 months before pregnancy

32 months after transplantation

8 months before pregnancy

40 months after transplantation

3 years after childbirth
Relevant Past Medical History

Hemodialysis was initiated due to lgA nephropathy.

Her first pregnancy resulted in spontaneous abortion.

Embryo cryopreservation was performed.

Summary

The patient was referred for kidney transplantation.

ABO-incompatible living-donor kidney transplant using rituximab was performed.

The patient was converted from mycophenolate mofetil to azathioprine.

Frozen embryo transfer was performed during the hormone replacement cycle.

She delivered a healthy baby but with a low birth weight.

The patient is in good clinical condition with only mild renal insufficiency. 
high proportion of multiple pregnancies [12]. There were 9 reports (16 pregnancies) published covering successful pregnancy outcomes after IVF in kidney transplant recipients [13-20]. Nine pregnancies were preterm, before 37 completed weeks of gestational age, and 4 pregnancies were twins. Previous reports showed that careful selection of women with kidney transplantation for IVF treatment may result in outcomes compatible to those in women who undergo kidney transplant and spontaneous conception [19]. In the present case, cesarean section was performed at 37 weeks and 4 days, and a healthy baby was delivered with a low birth weight $(2220 \mathrm{~g})$. This birthweight was very slightly lighter than the birthweight of the 10th centile at 37 weeks and 4 days gestation in the Japanese baby girl neonatal growth chart $(2232 \mathrm{~g})$ [21]. Although this finding may be a clinically relevant adverse outcome, it does not necessarily mean that IVF treatment should be avoided for women who had received ABOIKT.

Although hyperprolactinemia in women with ESKD has been well documented, its mechanism is still not clear. In ESKD patients, serum luteinizing hormone and follicle-stimulating hormone concentrations increase while serum progesterone concentrations decrease. The increase in gonadotropin levels is attributable to the loss of negative feedback on hypothalamic and pituitary centers, and the luteinizing hormone surge is blocked. This abnormal hypothalamus-pituitary-ovarian axis leads to menstrual cycle irregularity, anovulation, decreased libido, and impaired fertility. It has been reported that at 2 to 3 weeks after kidney transplantation, there is a temporary improvement in hypogonadotropic hypogonadism, which is followed by normalization of hypothalamicgonadal functions. The levels of circulating sex steroids remain suppressed and return to normal levels at 6 months after transplantation [22]. Moreover, although immunosuppressants have been reported to be teratogenic based on animal experiments, previous studies have confirmed safety of some agents in pregnancy. Women transplant patients receiving immunosuppressants whose safety has not been established must therefore be converted to those whose safety has been confirmed. Pregnancy can cause hyperfiltration, intrarenal vasodilation, and increased effective plasma flow without elevating intraglomerular pressure. It has also been reported that a renal allograft can adapt to the physiological changes of pregnancy in which creatinine clearance increases approximately $30 \%$ in the first trimester, slightly decreases in the second trimester and returns to pre-pregnancy levels during the third trimester. In addition, glomerular hyperfiltration during pregnancy is known to be transient and not accompanied by permanent renal impairment [23].

The optimal time to conception after kidney transplant remains controversial. Moreover, no reports have been made on the optimal time after ABO-IKT. In this case, we advised her to wait at least 2 years after ABO-IKT to ensure the safety of pregnancy, in reference to European best practice guidelines for kidney transplantation [24]. In pregnancies of kidney transplant recipients, major maternal complications are hypertension and pre-eclampsia, and major fetal complications are preterm delivery, low birth weight, and small for gestational age [7]. In this case, there were temporary hypertension, elevation of albuminuria, low birth weight, and small for gestational age, but no pre-eclampsia and preterm delivery. The albumin to creatinine ratio increased, $100-400 \mathrm{mg} / \mathrm{g}$, during three months of pregnancy and a year after delivery (Fig. 1). There is a possibility that delivery contributed to the decline in graft function. However, transplant biopsy undertaken a year after delivery showed no significant pathological changes.

In conclusion, our case demonstrated that it was possible for women who received ABO-IKT with rituximab to successfully become pregnant and deliver a heathy baby after IVF, if IgG levels recover to normal range despite depleted peripheral B cells Further research is needed to establish the optimal time for conception and safety of IVF after ABO-IKT with rituximab.

\section{Abbreviations}

ABO-IKT: ABO-Incompatible kidney transplantation; IVF: In vitro fertilization

\section{Acknowledgements}

Not applicable.

\section{Authors' contributions}

We would like to note that among the authors; JU, YY, NK, TN: Conception and design of the study. JU, AK: Writing the paper.

$J U, A H, H S$. TI, NK, KK: Participation in the patient's follow-up. AK, TN, SN, YT; Acquisition of data. KM: Management of the patient as a transplant recipient coordinator. All authors have made significant contributions to this paper and confirm the data to be beneficial for physicians involved in kidney transplantation. We have read and approved the final draft and confirm this work has not been previously published nor submitted simultaneously to any other journal.

\section{Authors' information}

Not applicable.

Funding

The authors received no specific funding for this work.

Availability of data and materials

Not applicable.

Ethics approval and consent to participate

Not applicable

Consent for publication

Written informed consent was obtained from the patient for publication of this Case Report and any accompanying images. A copy of the written consent is available for review by the Editor of this journal.

Competing interests

The authors declare that they have no competing interests. 


\section{Author details}

Department of Urology, Osaka City University Graduate School of Medicine, 1-4-3, Asahi-machi, Abeno-ku, Osaka 545-8585, Japan. ${ }^{2}$ Department of Nursing, Osaka City University Hospital, 1-5-7, Asahi-machi, Abeno-ku, Osaka 545-8586, Japan. ${ }^{3}$ Osaka City University Medical School Skills Simulation Center, 1-2-7, Asahi-machi, Abeno-ku, Osaka 545-0051, Japan. ${ }^{4}$ Department of Obstetrics and Gynecology, Osaka City University Graduate School of Medicine, 1-4-3, Asahi-machi, Abeno-ku, Osaka 545-8585, Japan. ${ }^{5}$ Department of Urology, Suita Municipal Hospital, 2-13-20, Katayama-cho, Suita-shi, Osaka 564-0082, Japan

\section{Received: 8 October 2018 Accepted: 24 May 2019}

Published online: 06 June 2019

\section{References}

1. Wiles KS, Nelson-Piercy C, Bramham K. Reproductive health and pregnancy in women with chronic kidney disease. Nat Rev Nephrol. 2018;14:165-84.

2. Hou S. Pregnancy in chronic renal insufficiency and end-stage renal disease. Am J Kidney Dis. 1999:33:235-52.

3. Davison JM. Dialysis, transplantation, and pregnancy. Am J Kidney Dis. 1991; 17:127-32.

4. Takahashi K, Sonda K, Okuda H, Nakazawa H, Kawaguchi $H$, Toma H, et al. The first report of a successful delivery in a woman with an ABOincompatible kidney transplantation. Transplantation. 1993:56:1288-9.

5. Esposito L, Rostaing L, Kamar N. Successful pregnancy after ABOincompatible kidney transplantation. Transpl Int. 2016:29:506-7.

6. Rao NN, Wilkinson C, Morton M, Bennett GD, Russ GR, Coates PT, Jesudason S. Successful pregnancy in a recipient of an $A B O$ incompatible renal allograft. Obstetric Med. 2018;0:1-3.

7. Shah S, Verma P. Overview of pregnancy in renal transplant patients. Int J Nephrol. 2016;2016:4539342.

8. Vijayan M, Pavlakis M. Pregnancy and the kidney transplant recipient. Curr Opin Nephrol Hypertens. 2017;26:494-500.

9. Sacco KA, Abraham RS. Consequences of B-cell-depleting therapy: hypogammaglobulinemia and impaired B-cell reconstitution. Immunotherapy. 2018;10:713-28.

10. Roberts DM, Jones RB, Smith RM, Alberici F, Kumaratne DS, Burns S, et al. Rituximab-associated hypogammaglobulinemia: incidence, predictors and outcomes in patients with multi-system autoimmune disease. J Autoimmun. 2015;57:60-5.

11. Uchida J, Machida Y, Iwai T, Kuwabara N, Kabei K, Naganuma T, et al. Conversion of stable $\mathrm{ABO}$-incompatible kidney transplant recipients from mycophenolate mofetil with standard exposure calcineurin inhibitors (CNIs) to everolimus with very low exposure CNIs-a short-term pilot study. Clin Transpl. 2014;28:80-7.

12. Helmerhorst FM, Perquin DA, Donker D, Keirse MJ. Perinatal outcome of singletons and twins after assisted conception: a systematic review of controlled studies. BMJ. 2004 Jan 31:328:261.

13. Lockwood GM, Ledger WL, Barlow DH. Successful pregnancy outcome in a renal transplant patient following in-vitro fertilization. Hum Reprod. 1995;10: 1528-30.

14. Furman B, Wiznitzer A, Hackmon R, Gohar J, Mazor M. Multiple pregnancies in women after renal transplantation. Case report that rises a management dilemma. Eur J Obstet Gynecol Reprod Biol. 1999:84:107-10.

15. Nouri K, Bader Y, Helmy S, Ott J, Jirecek S, Tempfer CB. Live birth after in vitro fertilization and single embryo transfer in a kidney transplant patient: a case report and review of the literature. J Assist Reprod Genet. 2011;28:3513.

16. Khalaf $Y$, Elkington $N$, Anderson $H$, Taylor A, Braude P. Ovarian hyperstimulation syndrome and its effect on renal function in a renal transplant patient undergoing IVF treatment: case report. Hum Reprod. 2000;15:1275-7.

17. Tamaki M, Ami M, Kimata N, Tsutsui T, Watanabe Y, Saito T, et al. Successful singleton pregnancy outcome resulting from in vitro fertilization after renal transplantation. Transplantation. 2003;75:1082-3.

18. Fichez A, Labrousse C, Fromajoux C, Bordes A, Hadj S, Audra P, et al. Successful pregnancy outcome after in vitro fertilization in a pancreaskidney recipient. Fertil Steril. 2008:90:849.e1-3.

19. Norrman E, Bergh C, Wennerholm UB. Pregnancy outcome and long-term follow-up after in vitro fertilization in women with renal transplantation. Hum Reprod. 2015;30:205-13.
20. Pietrzak B, Mazanowska N, Kociszewska-Najman B, Szymusik I, Grzechocińska B, Pazik J, et al. Successful pregnancy outcome after in vitro fertilization in a kidney graft recipient: a case report and literature review. Ann Transplant. 2015;20:338-41

21. Itabashi K, Miura F, Uehara R, Nakamura Y. New Japanese neonatal anthropometric charts for gestational age at birth. Pediatr Int. 2014;56:702-8.

22. Saha MT, Saha HH, Niskanen LK, Salmela KT, Pasternack Al. Time course of serum prolactin and sex hormones following successful renal transplantation. Nephron. 2002:92:735-7.

23. Kim HW, Seok HJ, Kim TH, Han DJ, Yang WS, Park SK. The experience of pregnancy after renal transplantation: pregnancies even within postoperative 1 year may be tolerable. Transplantation. 2008 May 27;85: 1412-9.

24. EBPG Expert Group on Renal Transplantation. European best practice guidelines for renal transplantation. Section IV. Long-term management of the transplant recipient. IV.10. Pregnancy in renal transplant recipients. Nephrol Dial Transplant. 2002:17 Suppl 4:50-5.

\section{Publisher's Note}

Springer Nature remains neutral with regard to jurisdictional claims in published maps and institutional affiliations.
Ready to submit your research? Choose BMC and benefit from:

- fast, convenient online submission

- thorough peer review by experienced researchers in your field

- rapid publication on acceptance

- support for research data, including large and complex data types

- gold Open Access which fosters wider collaboration and increased citations

- maximum visibility for your research: over $100 \mathrm{M}$ website views per year

At $\mathrm{BMC}$, research is always in progress.

Learn more biomedcentral.com/submissions 